\title{
Implantation of foldable posterior chamber intraocular lens in aphakic vitrectomized eyes without capsular support
}

\author{
Implantação lente intraocular dobrável de câmara posterior em olhos afácicos vitrectomizados sem \\ apoio capsular
}

Gurkan Erdogan ${ }^{1}$, Cihan Unluำ, Betul Onal Gunay ${ }^{1}$, Esra Kardes ${ }^{1}$, Ahmet Ergin ${ }^{1}$

\begin{abstract}
Purpose: To evaluate the outcomes of three different surgical techniques for foldable posterior chamber intraocular lens ( $\mathrm{PCIOL}$ ) implantation in vitrectomized eyes without capsular support.

Methods: A total of 60 patients with aphakic and vitrectomized eyes without capsular support were enrolled. All patients underwent three-piece foldable $\mathrm{PCIOL}$ implantation into the posterior chamber through a small corneal incision. Transscleral fixation (TSF), iris fixation (IF), and intrascleral tunnel fixation (ISF) surgical techniques were performed.

Results: Postoperative PCIOL subluxation or dislocation occurred in one case in the TSF group and two cases in the ISF group. Intraoperative PCIOL dislocation occurred in two patients in the IF group. The incidence of temporary postoperative complications, such as mild intraocular hemorrhage and cys toid macular edema, was higher in the ISF group. No statistically significan difference in PCIOL-related astigmatism was observed between groups. Visua acuity improved in all groups.

Conclusions: Postoperative outcomes were comparable between TSF, IF, and ISF for PCIOL in vitrectomized eyes without capsular support.
\end{abstract}

Keywords: Lens implantation, intraocular/methods; Iris/surgery; Suture techniques; Aphakia

\section{RESUMO}

objetivo: Avaliar os resultados de três diferentes técnicas cirúrgicas para implantação da lente intraocular de câmara posterior (PCIOL) dobrável em olhos vitrectomizados sem apoio capsular.

Métodos: Um total de 60 olhos de 60 pacientes afácicos vitrectomizados, sem apoio capsular foram inscritos. Todos os pacientes foram submetidos ao implante de PCIOL dobrável de três peças na câmara posterior, através de uma pequena incisão na córnea. Foram utilizados as técnicas cirúrgicas de fixação transescleral (TSF), fixação iriana (IF) e túnel de fixação intraescleral (ISF).

Resultados: Subluxação ou luxação da PCIOL ocorreu em um caso no grupo TSFe em dois casos no grupo ISF. Deslocamentos intraoperatórios da PCIOL ocorram em dois pacientes no grupo IF. Frequência de complicações pós-operatórias temporárias como hemorragia intraocular leve e edema macular cistóide foi maior no grupo ISF. Não houve diferença estatisticamente significativa do astigmatismo relacionado à PCIOL entre os grupos. A acuidade visual melhorou em todos os grupos.

Conclusões: Nenhuma das três técnicas cirúrgicas teve destaque em termos de resultados cirúrgicos comparativos.

Descritores: Implante de lente intraocular/métodos; /ris/cirurgia; Técnicas de sutura; Afacia

\section{INTRODUCTION}

The capsule of the crystalline lens, if sufficiently present, is used as a support tissue for intraocular lens (IOL) implantation surgery performed on vitrectomized eyes. Eye trauma or iatrogenic damage during complicated cataract surgery, loss of position and zonule connections of the crystalline lens, and IOL via dislocation may cause loss of support tissue for lens capsule implantation prior to pars plana vitrectomy (PPV). During PPV, the iatrogenic removal of the lens capsule may be required depending on the etiology and severity of the vitreoretinal disease. Posterior chamber IOL implantation may be performed via posterior chamber transscleral fixation ${ }^{(1-7)}$, iris fixation ${ }^{(8-11)}$, intrascleral fixation ${ }^{(12-22)}$, angle supported anterior chamber $I L^{(23,24)}$, or iris claw IOL implantation ${ }^{(25,26)}$.

Advantages of PCIOL fixation include the distant position from anterior segment structures, such as the corneal endothelium, and proximity to the focal point of the eye where the lens is naturally situated. However, the lack of the volume creation and supporting effect of the vitreous, and the fact that the surgery is generally performed under irrigation fluid, may complicate PCIOL fixation in vitrectomized eyes. In these cases, a small corneal tunnel incision may be used to create a closed and more stable surgical space. In cases with no capsular support, the implantation of a foldable IOL can be performed through a small corneal incision into the posterior chamber with suture fixation to the sclera or iris ${ }^{(4-11)}$. Alternatively, IOL implantation can be performed through a small incision to the posterior chamber with sutureless intrascleral fixation ${ }^{(12-22)}$.

In the present study, we evaluated three separate groups of patients with vitrectomized aphakic eyes lacking capsular support in whom foldable IOL were implanted through a small corneal incision using either transscleral fixation, iris fixation, or intrascleral fixation. Outcomes and complications were compared between the surgical methods. 


\section{METHODS}

We performed a retrospective observational case-controlled study of vitrectomized aphakic eyes in patients who had undergone foldable intraocular lens implantation into the posterior chamber. Patients lacking capsular support were divided into three groups according to the surgical intervention received between January 2008 and December 2014. Transscleral fixation was performed between January 2008 and June 2010 (TSF group), iris fixation between April 2010 and May 2012 (IF group), and intrascleral fixation since April 2012 (ISF group). In the ISF group, we did not include the initial eight cases of IOL implantation using folding method rather than injection during the learning period. We included consecutive cases that had undergone surgery between August 2012 and December 2014. Ethical approval for present the study was obtained from the local ethics committee. Detailed informed consent was obtained from each patient. The present study followed the tenets of the Declaration of Helsinki.

Ophthalmic examinations, including best-corrected visual acuity (BCVA) and intraocular pressure (IOP) measurements, dilated intraocular slit-lamp examination, autorefractometry, keratometry, and spectral domain optical coherence tomography (SD-OCT) (Optovue Inc., Fremont, CA) evaluation were performed during preoperative and postoperative study visits. Preoperative ocular condition, and intraoperative, and postoperative complications were evaluated. Astigmatism related to IOL was detected using "power vector analysis $(\mathrm{PVA})$ " with the consideration of preoperative and final examination keratometry values. The incidence of postoperative astigmatism related to IOL and BCVA was compared between groups. Patients with a follow-up period of $<3$ months or with preoperative corneal opacity were excluded from the study.

\section{SURGical METHODS}

All surgeries were performed by one surgeon (G.E). Retrobulbar anesthesia was performed in all patients. Continuous anterior chamber or pars plana infusion was used during surgery. A three-piece $\mathrm{IOL}$ (Sensar AR40e; Abbott Medical Optics, USA) was inserted through a superior clear corneal incision in all techniques. In cases with a dislocated IOL, exchange was performed if a single-piece IOL was present. However, the primary IOL was used for fixation if a three-piece IOL was present.

\section{TRANSSCLERAL FIXATION TECHNIQUE}

Transscleral fixation of foldable PCIOL was performed using the method described by Lewis ${ }^{(27)}$. Local conjunctival peritomies were performed on quadrants 3 and 9 followed by formation of the limbus based partial-thickness triangular flaps at $180^{\circ}$. A straight needle carrying 10-0 polyprolene was inserted into the posterior chamber under a scleral flap and was removed from beneath the opposite scleral tissue with the guidance of a 27 -gauge needle. A $3.5-\mathrm{mm}$ corneal incision was performed superiorly. The suture traversing the posterior chamber was pulled under the pupil with the assistance of a hook and removed from the main incision, cut, and then tied to the IOL haptics. The IOL was folded on the 6 o'clock and 12 o'clock axis and placed into the anterior chamber. Sutures were gently pulled to centralize the $\mathrm{IOL}$. The polyprolene sutures were tied under the scleral flaps and the conjunctiva was closed using an 8-0 polyglactin suture.

\section{IRIS FIXATION TECHNIOUE}

Iris fixation of foldable PCIOL was performed using the method described by Condon ${ }^{(8)}$. Pupillary constriction was provided by preoperative application of $4 \%$ topical pilocarpine. Paracentesis was applied with a 23-gauge MVR at 3, 6, and 9 o'clock. The IOL was folded into the desired shape, such that the haptics were in a mustache configuration, and placed through the corneal incision at 12 o'clock into the anterior chamber in a captured position with both haptics placed into the posterior iris extending into the 3 and 9 o'clock quadrants. In order to prevent posterior dislocation of the lens, the optic body was posteriorly supported with a spatula inserted at 6 o'clock. The optic was mildly elevated superiorly with a spatula to visualize the haptic under the iris. Using a modified McCannel-type technique, a 10-0 polyprolene suture was passed under the haptic and retrieved through the proximal paracentesis before the haptic was fixed to the peripheral iris. Similarly, the other haptic was sutured, with the optic manipulated into the posterior chamber.

\section{INTRASCLERAL FIXATION TECHNIQUE}

Intrascleral fixation of foldable PCIOL was performed via injection using a similar method as described by Gabor and Pavlidis ${ }^{(12)}$. The conjunctiva was opened at two clock-hour in the superior and inferior quadrants prior to cauterization. Scleral tunnels of $3 \mathrm{~mm}$ length were formed $1.5 \mathrm{~mm}$ from, and parallel to, the limbus using a 25-gauge trocar blade at the 6 o'clock and 12 o'clock positions. Infusions were then instilled into the anterior chamber or pars plana. A clear incision of $3 \mathrm{~mm}$ was made superiorly before the creation of a side port incision at 3 o'clock using a 23 MVR blade at the cornea. The leading haptic at the edge of the cartridge was grasped using 25-gauge forceps in the inferior scleral tunnel. The optic was then opened in the anterior chamber gradually while the cartridge was withdrawn and the trailing haptic unfolded outside the anterior chamber through the corneal incision. The leading haptic was externalized from the inferior scleral tunnel. Consequently, the trailing haptic was transferred from the superior corneal incision to the 23-gauge forceps in the side port at the 3 o'clock position and later grasped by the 25-gauge forceps in the superior scleral tunnel using the handshake technique ${ }^{(22)}$ and externalized. The haptics were fixed by suturing around the scleral tunnels with 8-0 polyglactin suture and the conjunctiva was closed.

\section{Statistical analysis}

NCSS (Number Cruncher Statistical System) 2007 \& PASS (Power Analysis and Sample Size 2008 Statistical Software, Utah, USA) were used for statistical analyses. BCVA values were converted to logarithm of the minimum angle of resolution (logMAR) units in all patients. The Kruskal-Wallis test was used to compare three and more groups demonstrating abnormal distributions. The Mann-Whitney $U$ test was used to compare qualitative data between groups. The Wilcoxon signed rank test was used intra-group comparisons of parameters demonstrating an abnormal distribution. P-values of $<0.05$ were considered statistically significant.

\section{RESULTS}

The present study included 60 patients (60 aphakic vitrectomized eyes) without sufficient capsular support. No significant difference in patient age was observed between groups ( $P=0.50)$. Table 1 summarizes the demographic characteristics of the study population. Ocular conditions prior to IOL implantation are shown in table 2.

Table 3 presents the timings of IOL implantation. BCVA changes before and after surgery are provided in table 4 . Statistically significant increases in visual acuity were observed postoperatively in all groups, except for the TSF group in which there was a trend toward increased BCVA postoperatively ( $P=0.092)$. No significant differences in preoperative VA were observed between groups $(P=0.123)$; however, postoperative values were found to differ significantly between groups $(P=0.003)$. Postoperative VA values were highest in the IF group. No significant difference in BCVA was observed between groups $(P=0.790)$

Intraoperative complications were observed only in the IF group. Intraoperative IOL dislocation occurred in two patients, with one instance of recurrence observed in one of these patients. Postoperative complications are summarized in table 5. Mild temporary intraocular 
hemorrhage $(\mathrm{IOH})$, which resolved in 1-3 weeks, and postoperative cystoid macular edema (CME), demonstrated by optical coherence tomography, were more common among patients in the ISF group.

Table 1. Baseline characteristics and ophthalmic data

\begin{tabular}{lc}
\hline Number of eyes & 60 \\
Age, yrs (mean \pm SD) & $65.6 \pm 12.2$ \\
Male/female & $53 / 36$ \\
Type of IOL implantation & \\
Transscleral fixation & 13 \\
Iris fixation & 17 \\
Intrascleral fixation & 30 \\
Follow up, months (mean \pm SD) & $7.0 \pm 3.7$ \\
\hline IOL= intraocular lens: SD= standard deviation. &
\end{tabular}

Table 2. Ocular conditions prior to IOL implantation

\begin{tabular}{lccc}
\hline & $\begin{array}{c}\text { TSF } \\
\text { group }\end{array}$ & $\begin{array}{c}\text { IF } \\
\text { group }\end{array}$ & $\begin{array}{c}\text { ISF } \\
\text { group }\end{array}$ \\
\hline IOL subluxation/dislocation & 1 & 5 & 7 \\
Crystalline lens subluxation/dislocation & 5 & 4 & 3 \\
Dislocated lens fragments during cataract surgery & 4 & 3 & 5 \\
Capsular damage during cataract surgery & 3 & 3 & 3 \\
Trauma/intraocular foreign body & & 1 & 6 \\
Endophthalmitis & & 1 & 6 \\
\hline
\end{tabular}

$\mathrm{IOL}=$ intraocular lens; $\mathrm{TSF}=$ transscleral fixation; $\mathrm{IF}=$ iris fixation; $\mathrm{ISF}=$ intrascleral fixation.

Table 3. Timing of IOL implantation

\begin{tabular}{lcc}
\hline & \multicolumn{2}{c}{ Time of IOL implantation } \\
\cline { 2 - 3 } Groups & During PPV, $\mathbf{n}$ (\%) & After PPV, $\mathbf{n}(\%)$ \\
\hline All groups & $16(27)$ & $44(73)$ \\
TSF group & $3(23)$ & $10(77)$ \\
IF group & $4(23)$ & $13(77)$ \\
ISF group & $9(30)$ & $21(70)$ \\
\hline
\end{tabular}

$\mathrm{IOL}=$ intraocular lens; $\mathrm{PPV}=$ pars plana vitrectomy; $\mathrm{TSF}=$ transscleral fixation; $I F=$ iris fixation; ISF= intrascleral fixation.

Table 4. Preoperative and postoperative best-corrected visual acuities

\begin{tabular}{lcccc}
\hline & TSF group & IF group & ISF group & \\
\hline $\begin{array}{l}\text { Preoperative BCVA (logMAR) } \\
\text { (mean } \pm \text { SD) }\end{array}$ & $1.36 \pm 0.99$ & $0.94 \pm 0.71$ & $1.33 \pm 0.79$ & 0.123 \\
$\begin{array}{l}\text { Postperative BCVA (logMAR) } \\
\text { (mean } \pm \text { SD) }\end{array}$ & $0.89 \pm 0.84$ & $0.40 \pm 0.30$ & $0.84 \pm 0.42$ & $0.003^{* *}$ \\
$\begin{array}{l}\text { bP-value } \\
\begin{array}{l}\text { Change in BCVA } \\
\text { (mean }+ \text { SD) }\end{array}\end{array}$ & 0.092 & $0.001^{* *}$ & $0.00^{* *}$ & \\
\hline
\end{tabular}

(mean \pm SD)

$\mathrm{SD}=$ standard deviation; $\mathrm{BCVA}=$ best-corrected visual acuity; logMAR= logarithm of the minimum angle of resolution; TSF= transscleral fixation; IF= iris fixation; ISF= intrascleral fixation.

${ }^{a}=$ Kruskal-Wallis test: ${ }^{b}=$ Wilcoxon signed ranks test ${ }^{c}=$ Mann-Whitney $U$ test.

${ }^{*}=\mathrm{P}<0.05 ;{ }^{* *}=\mathrm{P}<0.01$.
CME occurred 1-3 months postoperatively and resolved within 6 months in all patients. Postoperative endophthalmitis was not observed in the present study.

No statistically significant difference between in the incidence of IOL-related astigmatism, calculated according to the PVA method, was observed between groups. However, while mean IOL-related astigmatism values were 0.91 diopter (D) in the IF group and $1.35 \mathrm{D}$ in the ISF group, a value of $1.65 \mathrm{D}$ was observed in the TSF group $(P=0.20 ;$ Table 6)

\section{DISCUSSION}

The vitreous humor plays an important role in providing structure and volume due to its semi-solid gel-like properties. In a proportion of vitrectomized eyes, in addition to reduced amounts of vitreous humor, the eye anatomy may be altered due to surgery, trauma, inflammation, and natural events such as old age and myopia, leading to decreased scleral rigidity. The creation of a stable surgical environment in vitrectomized eyes during anterior segment surgery is typically challenging, and IOP regulation may be provided via anterior chamber or pars plana continuous fluid infusion.

In order to maintain stable and consistent vitreal volumes, lowfluctuating IOP (i.e., a balance between entering and exiting fluids) is required. As the incision is extended, it becomes more difficult to maintain stable and maintained IOP. Further, fluid regurgitation, sudden pressure drops, and risk of collapse all increase with surgical manipulations. Young et al. ${ }^{(28)}$ attempted to overcome these challenges using a scleral tunnel incision rather than a corneal incision. Further, the use of bridle sutures in the rectus muscle reportedly have utility in preventing globe collapse intraoperatively ${ }^{(5)}$.

The presence or absence of capsular support in vitrectomized eyes is important in determining the most appropriate surgical approach. While the surgical method is simple and evident in eyes with capsular support, the lack of a capsule requires the use of more complex surgical procedures. Posterior chamber implantation has many advantageous over anterior chamber implantation - the IOL is distant from the sensitive anterior chamber structures, aqueous flow

\section{Table 5. Postoperative complications}

\begin{tabular}{lccc}
\hline & TSF group & IF group & ISF group \\
\hline ERM & & & 1 \\
CME & 1 & 1 & 4 \\
Secondary glaucoma & & 1 & \\
Transient intraocular pressure rise & 3 & 1 & 5 \\
Temporary IOH & 1 & & 4 \\
Dense IOH & & 1 & \\
IOL subluxation/dislocation & 1 & & 3 \\
Retinal detachment & & 1 & 1 \\
Temporary corneal edema & & & 1 \\
\hline TSF- transslixation
\end{tabular}

TSF= transscleral fixation; IF= iris fixation; ISF= intrascleral fixation; $E R M=$ epiretinal membrane; $\mathrm{CME}=$ cystoid macular edema; $\mathrm{IOH}=$ intraocular hemorrhage; $\mathrm{IOL}=$ intraocularlens.

Table 6. Postoperative IOL related astigmatism

\begin{tabular}{lcccc}
\hline & TSF group & IF group & ISF group & aP-value \\
\hline $\begin{array}{l}\text { IOL related astigmatism } \\
\text { (mean } \pm \text { SD) }\end{array}$ & $1.65 \pm 1.00$ & $0.91 \pm 0.40$ & $1.35 \pm 1.67$ & 0.200 \\
\hline
\end{tabular}

$\mathrm{SD}=$ standard deviation; TSF= transscleral fixation; $\mathrm{IF}=$ iris fixation; $I S F=$ intrascleral fixation; $\mathrm{IOL}=$ intraocular lens.

$\mathrm{a}=$ Kruskal-Wallis test 
paths, and cornea endothelium. Further, placement of the IOL close to the natural position of the crystalline lens has particular optical advantages.

Of the 13 patients that received ISF, CME was observed in one, $\mathrm{IOL}$ subluxation in one, and temporary $\mathrm{IOH}$ in one. Ahn et al. ${ }^{(5)}$ performed foldable IOL transscleral fixation on 21 vitrectomized eyes. The authors observed temporary $1 \mathrm{OH}$ in one patient and a reopened macular hole in one. Kaynak et al. ${ }^{(6)}$ used a similar surgical technique on a series of 20 patients (of whom half were vitrectomized eyes), and reported suture erosion in two patients and CME in two patients. In studies in which transscleral fixation was applied with a large incision in vitrectomized eyes, higher complication rates of 39\%-49\% were reported in patients required repeat surgery ${ }^{(1-3)}$. A disadvantage of sutures in scleral fixation is the potential development of suture erosion over time ${ }^{(3,29)}$. We observed IOL subluxation in one patient in the present study. In the present study population of 13 cases, we observed a mean lens-related astigmatism of $1.65 \mathrm{D}$ according to PVA measurements. There was a trend toward higher values in the TSF group than in the other groups.

In the second group, we applied the iris fixation technique in 17 patients. As the lens is stabilized parallel to the iris plane during iris fixation, IOL-related astigmatism was less in this group (0.91 D). In aphakic victrectomized eyes, the iris may be mid-dilated and iris atrophy leading to difficult iris fixation under fluid infusion may be observed. During the present study, we encountered posterior segment IOL dislocation in two cases, occurring twice in one case during the same procedure. Further, it is not always possible to maintain a round and regular pupil during iris fixation, with an associated risk of poor dilatation often during the postoperative period. We detected CME in one patient, secondary glaucoma in one, dense $\mathrm{IOH}$ in one, and retinal detachment in one. Complication rates were comparable in the present study to similar previous studies ${ }^{(0,10)}$. Previous studies have used iris claw lenses for iris fixation to correct aphakia in vitrectomized eyes ${ }^{(25,26)}$. While the lack of suture usage was an advantage in these studies, the requirement of a large incision and anterior chamber implantation were disadvantages ${ }^{(25,26)}$.

Two major methods of suture-free intrascleral IOL implantation have been reported in previous literature. In this technique, the haptics are fixated under scleral flaps using tissue adhesive glue ${ }^{(20-22)}$ or into a narrow scleral tunnel parallel to the limbus ${ }^{(12-19)}$. Fixation into the scleral tunnel has advantages, such as removing the requirement need for an additional tissue adherent or the use of scleral flaps. In the third group of the present study, we applied the intrascleral tunnel fixation technique in 30 patients. In contrast to previous studies, the haptics of the IOL were sutured with polyglactin sutures in order to achieve better early postoperative fixation in vitrectomized eyes. We detected ERM in one patient, CME in four, temporary $\mathrm{IOH}$ in four, IOL subluxation/dislocation in three, and retinal detachment in one. Temporary $\mathrm{IOH}$ and postoperative CME were also observed more frequently in this group. Temporary $\mathrm{IOH}$ at 1-3 weeks and CME at 6 months completely resolved during the study period. These postoperative complications have also been reported in similar previously-reported studies ${ }^{(13,16-19)}$.

No significant difference in VA change was observed between groups in the present study $(P=0.79)$ While there was no difference in preoperative VA, a statistical difference between postoperative $V A$ values was observed between groups ( $P=0.003)$. In the IF group, patients had higher VA values. The non-uniform diagnosis of patients between groups and the reduced sample size may have influenced postoperative visual outcomes and resulted in the observed differences between groups.

In conclusion, none of the three surgical techniques were associated with superior postoperative results, with no prominence observed in terms of comparative surgical outcomes. The present study was limited by a lack of randomization and the time difference between the three groups. Further controlled studies in larger study samples may provide further information regarding the relative efficacy of these techniques.

\section{REFERENCES}

1. Johnston RL, Charteris DG, Horgan SE, Cooling RJ. Combined pars planavitrectomy and sutured posterior chamber implant. Arch Ophthalmol. 2000;118(7):905-10.

2. Bading G, Hillenkamp J, Sachs HG, Gabel VP, Framme C. Long-term safety and functional outcome of combined pars plana vitrectomy and scleral-fixated sutured posterior chamber lens implantation. Am J Ophthalmol. 2007;144(3):371-377.

3. Vote BJ, Tranos P, Bunce C, Charteris DG, Da Cruz L. Long-term outcome of combined pars plana vitrectomy and scleral fixated sutured posterior chamber intraocular lens implantation. Am J Ophthalmol. 2006;141(2):308-312.

4. Regillo CD, Tidwell J. A small-incision technique for suturing a posterior chamber intraocular lens. Ophthalmic Surg Lasers. 1996;27(6):473-5.

5. Ahn JK, Yu HG, Chung H, Wee WR, Lee JH. Transscleral fixation of a foldable intraocular lens in aphakic vitrectomized eyes. J Cataract Refract Surg. 2003;29(12):2390-6.

6. Kaynak S, Ozbek Z, Pasa E, Oner FH, Cingil G. Transscleral fixation of foldable intraocular lenses. J Cataract Refract Surg. 2004;30(4):854-7.

7. Zhang ZD, Shen $L$, Liu XQ, Chen YQ, Qu J. Injection and suturing technique for scleral fixation foldable lens in the vitrectomized eye. Retina. 2010;30(2):353-6.

8. Condon GP. Simplified small-incision peripheral iris fixation of an AcrySof intraocular lens in the absence of capsule support. J Cataract Refract Surg. 2003;29(9):1663-7.

9. Condon GP, Masket S, Kranemann C, Crandall AS, Ahmed II. Small-incision iris fixation of foldable intraocular lenses in the absence of capsule support. Ophthalmology. 2007;114(7):1311-8.

10. Kopel AC, Carvounis PE, Hamill MB, Weikert MP, Holz ER. Iris-sutured intraocular lenses for ectopia lentis in children. J Cataract Refract Surg. 2008;34(4):596-600.

11. Benevento JD, Ponce EA, Dayan AR. Injection of an intraocular lens in an eye without capsular support. J Cataract Refract Surg. 2007;33(1):15-8.

12. Gabor SG, Pavlidis MM. Sutureless intrascleral posterior chamber intraocularlens fixation. J Cataract Refract Surg. 2007;33(11):1851-4.

13. Scharioth GB, Prasad S, Georgalas I, Tataru C, Pavlidis M: Intermediate results of sutureless intrascleral posterior chamber intraocular lens fixation. J Cataract Refract Surg. 2010;36(2):254-9.

14. Prenner JL, Feiner L, Wheatley HM, Connors D. A novel approach for posterior chamber intraocular lens placement or rescue via a sutureless scleral fixation technique. Retina. 2012;32(4):853-5.

15. Totan Y, Karadag R. Trocar-assisted sutureless intrascleral posterior chamber foldable intra-ocular lens fixation. Eye. 2012;26(6):788-91.

16. Prasad S. Transconjunctival sutureless haptic fixation of posterior chamber IOL: a minimally traumatic approach for IOL rescue or secondary implantation. Retina. 2013; 33(3):657-60

17. Ohta T, Toshida H, Murakami A. Simplified and safe method of sutureless intrasclera posterior chamber intraocular lens fixation: Y-fixation technique. J Cataract Refract Surg. 2014;40(1):2-7.

18. Yamane S, Inoue M, Arakawa A, Kadonosono K. Sutureless 27-gauge needle-guided intrascleral intraocular lens implantation with lamellar scleral dissection. Ophthalmology. 2014;121(1):61-6.

19. Liu S, Cheng S. Modified method of sutureless intrascleral posterior chamber intraocular lens fixation without capsular support. Eur J Ophthalmol. 2013;23(5):732-7.

20. Agarwal A, Kumar DA, Jacob S, Baid C, Agarwal A, Srinivasan S. Fibrin glue-assisted sutureless posterior chamber intraocular lens implantation in eyes with deficient posterior capsules. J Cataract Refract Surg. 2008;34(9):1433-8.

21. Kumar DA, Agarwal A, Prakash D, Prakash G, Jacob S, Agarwal A. Glued intrascleral fixation of posterior chamber intraocular lens in children. Am J Ophthalmol. 2012; 153(4):594-601

22. Agarwal A, Jacob S, Kumar DA, Agarwal A, Narasimhan S, Agarwal A. Handshake technique for glued intrascleral haptic fixation of a posterior chamber intraocular lens. J Cataract Refract Surg. 2013;39(3):317-22.

23. Malinowski SM, Mieler WF, Koenig SB, Han DP, Pulido JS. Combined pars plana vitrectomy-lensectomy and open-loop anterior chamber lens implantation. Ophthalmology. 1995;102(2):211-6.

24. Kazemi S, Wirostko WJ, Sinha S, Mieler WF, Koenig SB, Sheth BP. Combined pars plana lensectomy-vitrectomy with open-loop flexible anterior chamber intraocular lens ( $A C$ IOL) implantation for subluxated lenses. Trans Am Ophthalmol Soc. 2000;98:247-253.

25. Acar N, Kapran Z, Altan T, Kucuksumer Y, Unver YB, Polat E. Secondary iris claw intraocular lens implantation for the correction of aphakia after pars plana vitrectomy. Retina. 2010;30(1):131-9.

26. Riazi M, Moghimi S, Najmi Z, Ghaffari R. Secondary Artisan-Verysise intraocular lens implantation for aphakic correction in post-traumatic vitrectomized eye. Eye. 2008; 22(11):1419-24

27. Lewis JS. Ab externo sulcus fixation. Ophthalmic Surg. 1991;22(11):692-5

28. Young AL, Leung GY, Cheng LL, Lam DS. A modified technique of scleral fixated intraocular lenses for aphakic correction. Eye. 2005;19(1):19-22.

29. Price MO, Price FW Jr, Werner L, Berlie C, Mamalis N. Late dislocation of scleral-sutured posterior chamber intraocular lenses. J Cataract Refract Surg. 2005;31(7):1320-6. 